\title{
Ultrahigh Strength and High Electrical Conductivity Characteristics of Cu-Zr Alloy Wires with Nanoscale Duplex Fibrous Structure
}

\author{
Hisamichi Kimura $^{1}$, Akihisa Inoue ${ }^{1}$, Naokuni Muramatsu ${ }^{2}$, Keesam Shin $^{3}$ and Tokujiro Yamamoto ${ }^{1}$ \\ ${ }^{1}$ Institute for Materials Research, Tohoku University, Sendai 980-8577, Japan \\ ${ }^{2}$ NGK INSULATORS, LTD, Handa 475-0825, Japan \\ ${ }^{3}$ Dept. of Metallurgy and Materials Science School of Nano and Advanced Materials, Changwon National University, \\ 9 Sarim-dong, Changwon-city, Gyeungnam-do 641-773, Republic of Korea
}

The cold drawing of cast $\mathrm{Cu}_{100-x} \mathrm{Zr}_{x}(x=3,4$ and 5 at\%) alloys to the reduction ratio of $99.7 \%$ was found to cause simultaneous achievement of ultrahigh tensile strength of 1350 to $1800 \mathrm{MPa}$ and high electrical conductivity of 30 to $45 \%$ IACS (International Annealed Copper Standard). The cold-drawn $\mathrm{Cu}_{95} \mathrm{Zr}_{5}$ alloy wire has a well-developed fibrous structure of fcc-Cu and tetragonal $\mathrm{Cu}_{9} \mathrm{Zr}_{2}$ phases. The volume ratio of the fcc-Cu phase was evaluated to be about $76 \%$. A very high density of internal defects was observed inside the $\mathrm{Cu}_{9} \mathrm{Zr}_{2} \mathrm{phase} \mathrm{in}$ the cold-drawn $\mathrm{Cu}_{95} \mathrm{Zr}_{5}$ alloy. The microstructure data suggest that the $\mathrm{Cu}$ fibrous phase with high aspect ratios is the origin for the achievement of high electrical conductivity and the well-developed fibrous structure contributes to the high tensile strength. The success of synthesizing the $\mathrm{Cu}-\mathrm{Zr}$ alloy wire with simultaneously high tensile strength and high electrical conductivity exceeding the best combination of all $\mathrm{Cu}$-based alloys reported up to data is expected to be used as a new type of high-strength and high conductivity material because of some advantages of energy saving, low materials cost and simple production process. [doi:10.2320/matertrans.47.1595]

(Received December 6, 2005; Accepted April 14, 2006; Published June 15, 2006)

Keywords: copper-zirconium alloy, wire, tensile strength, electrical conductivity, fibrous structure

\section{Introduction}

In the present human society where a great large amount of electric power has been consumed, it is very important to develop an advanced material having simultaneously high mechanical strength and high electrical conductivity. It is well known that $\mathrm{Cu}$ metal has high electrical conductivity in conjunction with low materials cost. On the other hand, the highest strength of $\mathrm{Cu}$-based alloys has been reported to be 900 to $1500 \mathrm{MPa}$ for $\mathrm{Cu}-\mathrm{Be}$ base alloys subjected to an optimum age-hardening treatment ${ }^{1,2)}$ and 600 to $1500 \mathrm{MPa}$ for $\mathrm{Cu}-\mathrm{M}(\mathrm{M}=\mathrm{Nb}$ or $\mathrm{Ag})$ alloy wires produced by heavy cold drawing, ${ }^{3-6)}$ though disordered glassy alloys in $\mathrm{Cu}$-based alloy system exhibit much higher tensile fracture strength of 2000 to $2500 \mathrm{MPa}^{7-10)}$ On the other hand, the electrical conductivity is about 24 to $50 \%$ IACS for the age-hardened $\mathrm{Cu}-\mathrm{Be}$ alloys ${ }^{1,2)}$ and 50 to $90 \%$ IACS for the $\mathrm{Cu}-\mathrm{M}$ alloy wires. ${ }^{3-6)}$ Considering that the highest strength of crystalline metallic materials has been obtained for cold-rolled $\mathrm{Fe}-\mathrm{C}$ alloy (piano wire) with a fibrous structure consisting of $\alpha$-Fe ferrite and $\mathrm{Fe}_{3} \mathrm{C}$ cementite carbide, ${ }^{11,12)}$ it is expected that higher strength characteristics in $\mathrm{Cu}$-based alloys are obtained in $\mathrm{Cu}$-based alloys with the similar fibrous mixed structure. We looked for an optimum alloy system where a well-developed fibrous structure consisting of $\mathrm{Cu}$ and compound was formed by cold drawing. In the development of the fibrous structure alloys, we paid attention to the following three points; the volume fraction ratio of $\mathrm{Cu}$ to compound phase, the purity and continuity of $\mathrm{Cu}$ phase and the deformability of compound phase by cold drawing. Very recently, we have studied structure, mechanical properties and electrical conductivity for heavily cold-rolled $\mathrm{Cu}_{100-x} \mathrm{Zr}_{x}$ $(x=0-8)$ alloys. The results show that (1) the $\mathrm{Cu}_{95} \mathrm{Zr}_{5}$ alloy cold-rolled to the reduction of $98 \%$ has the lamellar structure of the primary crystallized fcc-Cu and the eutectic phase (fcc$\mathrm{Cu}+\mathrm{Cu}_{9} \mathrm{Zr}_{2}$ ) along to the direction of cold rolling, (2) the
$\mathrm{Cu}_{94} \mathrm{Zr}_{6}$ alloy has the highest strength of $1200 \mathrm{MPa}$ in the $\mathrm{Cu}_{100-x} \mathrm{Z}_{\mathrm{r}}$ alloys with $x=0.5-6$, (3) it has the 35\%IACS. We have pointed out that their mechanical and electrical properties have a close relation to the formation of the lamellar structure by cold-rolling. ${ }^{13)}$ This paper presents the microstructure mechanical strength and electrical conductivity of $\mathrm{Cu}-\mathrm{Zr}$ binary alloys subjected to cold drawing after casting and investigates the origin for the good characteristics.

\section{Experimental Procedure}

Binary alloy ingots with composition of $\mathrm{Cu}_{100-x} \mathrm{Zr}_{x}(x=3$, 4 and 5 at\%) were prepared by arc melting the mixtures of pure 99.9 mass $\% \mathrm{Cu}$ and 99 mass $\% \mathrm{Zr}$ metals in an argon atmosphere, followed by casting into copper mold with a rod shape cavity of $3 \mathrm{~mm}$ in inner diameter. The cast alloy rods were cold drawn to $0.16 \mathrm{~mm}$ in diameter by tool steel dies without intermediate annealing treatment. The resulting reduction ratio in cross section is estimated to be $99.7 \%$. The structure of the $\mathrm{Cu}-\mathrm{Zr}$ alloys in as-cast and cold-drawn states was examined by X-ray diffraction, optical microscopy and transmission electron microscopy (TEM). The TEM observation was made by using a transmission electron microscope (JEOL-200EX-II) linked with an energy dispersive X-ray scattering analytical equipment. The optical micrograph (OM) structure was observed after etching for $30 \mathrm{~s}$ at $298 \mathrm{~K}$ in a mixture of ammonium hydroxide $(3.5 \mathrm{cc})$, hydrogen oxide $(30 \% ; 1.5 \mathrm{cc})$ and distilled water $(5 \mathrm{cc})$. Electrical conductivity measurement was made by the fourprobe technique and international annealed copper standard sample with a resistivity of $1.7241 \mu \Omega \mathrm{cm}$ was used as the reference material of electrical conductivity. Mechanical properties (ultimate tensile strength, $0.2 \%$ proof strength and elongation) were measured at a strain rate of $4.2 \times 10^{-4} \mathrm{~s}^{-1}$ with an Instron type tensile testing machine at room temperature. These measurements were carried out three 

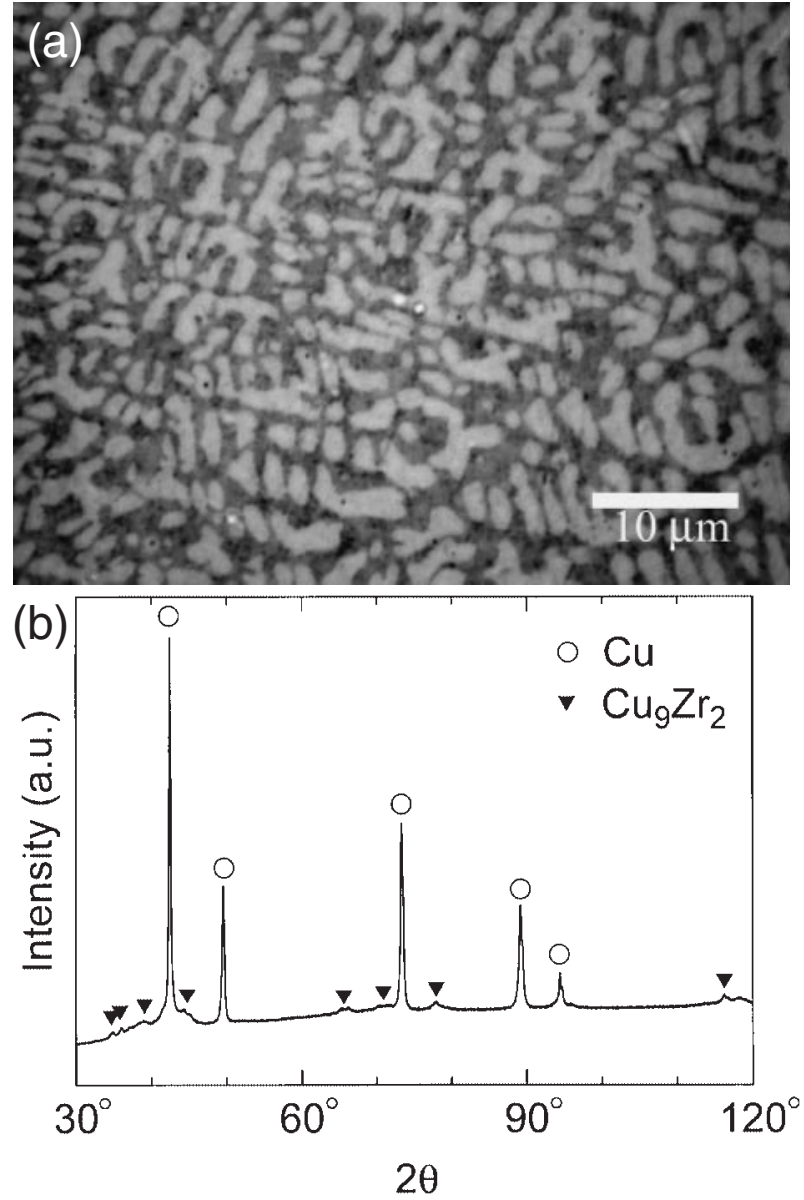

Fig. 1 Optical micrograph (a) and X-ray diffraction pattern (b) of transverse cross section of the $\mathrm{Cu}_{95} \mathrm{Zr}_{5}$ alloy rod with a diameter of $3 \mathrm{~mm}$ produced by copper mold casting (white part: a primary dendrite phase, black part: a eutectic structure).

Table 1 Compositions of white part and black one in optical photograph of Fig. 1 measured by EPMA at $20 \mathrm{kV}$.

\begin{tabular}{ccc}
\hline & $\mathrm{Cu} / \mathrm{at} \%$ & $\mathrm{Zr} / \mathrm{at} \%$ \\
\hline white part & 99.9 & 0.1 \\
black part & 90.2 & 9.8 \\
\hline
\end{tabular}

times for each sample of the cold drawn $\mathrm{Cu}_{100-x} \mathrm{Zr}_{x}(x=3,4$ and 5 at $\%$ ) alloy wires. The fracture behavior was examined by scanning electron microscopy (SEM). Vickers hardness was measured with a micro Vickers hardness tester (load: $25 \mathrm{~g})$.

\section{Results and Discussion}

Figure 1 shows X-ray diffraction pattern and optical photograph of the transverse cross section of a central part of the as-cast $\mathrm{Cu}_{95} \mathrm{Zr}_{5}$ alloy rod with a diameter of $3 \mathrm{~mm}$ produced by copper mold casting. The X-ray diffraction pattern can be identified as two phases of fcc-Cu and tetragonal $\mathrm{Cu}_{9} \mathrm{Zr}_{2}{ }^{14)}$ phases. The optical micrograph reveals that the fcc-Cu phase solidified as a primary dendrite phase from supercooled liquid, followed by the solidification to a eutectic structure from the remaining liquid. Table 1 shows compositions of white part and black one in optical micro-

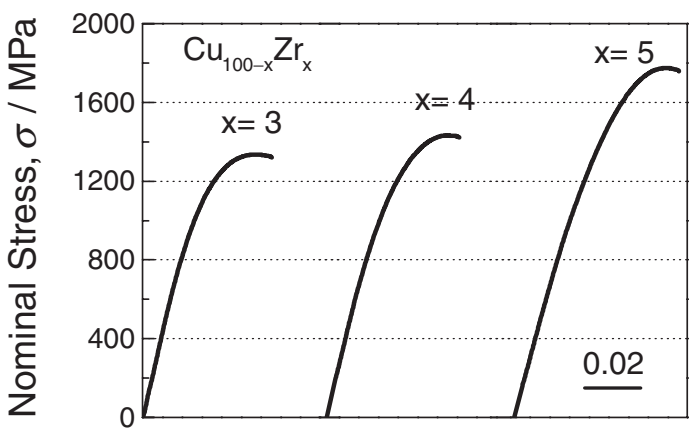

Nominal Strain, $\varepsilon$

Fig. 2 Nominal tensile stress-strain curves of the cold drawn $\mathrm{Cu}_{100-x} \mathrm{Zr}_{x}$ $(x=3,4$ and 5 at $\%)$ alloy wires.

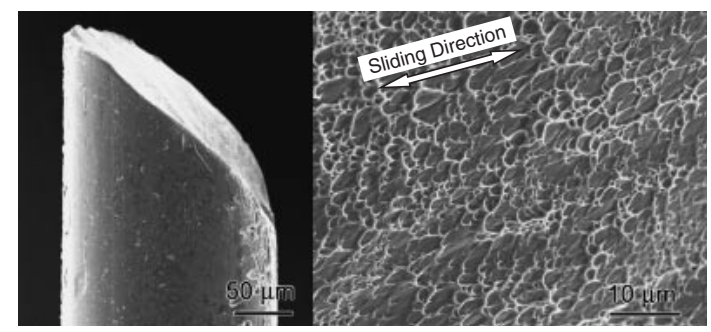

Fig. 3 SEM fractographs of fracture morphology (a) and fracture surface (b) of the cold drawn $\mathrm{Cu}_{95} \mathrm{Zr}_{5}$ alloy wire after tensile test.

graph of Fig. 1 measured by Electron Probe Micro-Analyzer (EPMA) at $20 \mathrm{kV}$. As shown in Table 1, the white part is the fcc-Cu phase containing 0.1 at $\% \mathrm{Zr}$ and the black part is considered to be the eutectic structure which consist of fcc$\mathrm{Cu}$ and $\mathrm{Cu}_{9} \mathrm{Zr}_{2}$ phases based on the results of X-ray diffraction. These results are consistent with that in equilibrium phase diagram ${ }^{15)}$ in which $\mathrm{Cu}_{95} \mathrm{Zr}_{5}$ alloy consists of fcc- $\mathrm{Cu}$ and tetragonal $\mathrm{Cu}_{9} \mathrm{Zr}_{2}$ phases at room temperature. The similar mixed structure is obtained for binary $\mathrm{Cu}_{97} \mathrm{Zr}_{3}$ and $\mathrm{Cu}_{96} \mathrm{Zr}_{4}$ alloys. The volume fraction of the fcc-Cu phase for the $\mathrm{Cu}_{100-x} \mathrm{Zr}_{x}$ (3, 4 and 5 at\%) alloy rods is evaluated to be about $83 \%, 80 \%$ and $76 \%$, respectively, in agreement with those expected from the equilibrium phase diagram. We also tried to clarify the transverse cross sectional structure of the $\mathrm{Cu}_{95} \mathrm{Zr}_{5}$ alloy subjected to cold drawing to $99.7 \%$ reduction in cross section by optical microscopy. However, both the fcc-Cu dendrite and eutectic phases were too fine to identify their microstructure. Figure 2 shows nominal tensile stressstrain curves of the cold drawn $\mathrm{Cu}_{100-x} \mathrm{Zr}_{x}(x=3,4$ and 5 at\%) alloy wires. It is characterized that these alloys have significant strain hardening in conjunction with distinct elongation of about 2.4\%. Figure 3 shows SEM fractographs of fracture morphology (a) and fracture surface (b) of the cold drawn $\mathrm{Cu}_{95} \mathrm{Zr}_{5}$ alloy wire after tensile test. Neither distinct yield point phenomenon nor reduction in cross section before fracture is recognized. The SEM fractograph in Fig. 3(a) shows that the tensile fracture takes place along the maximum shear stress plane which is declined by about 45 degrees to the direction of tensile applied load. As seen in SEM fractograph in Fig. 3(b), the fracture surface consists of a well-developed vein pattern over the whole fracture 


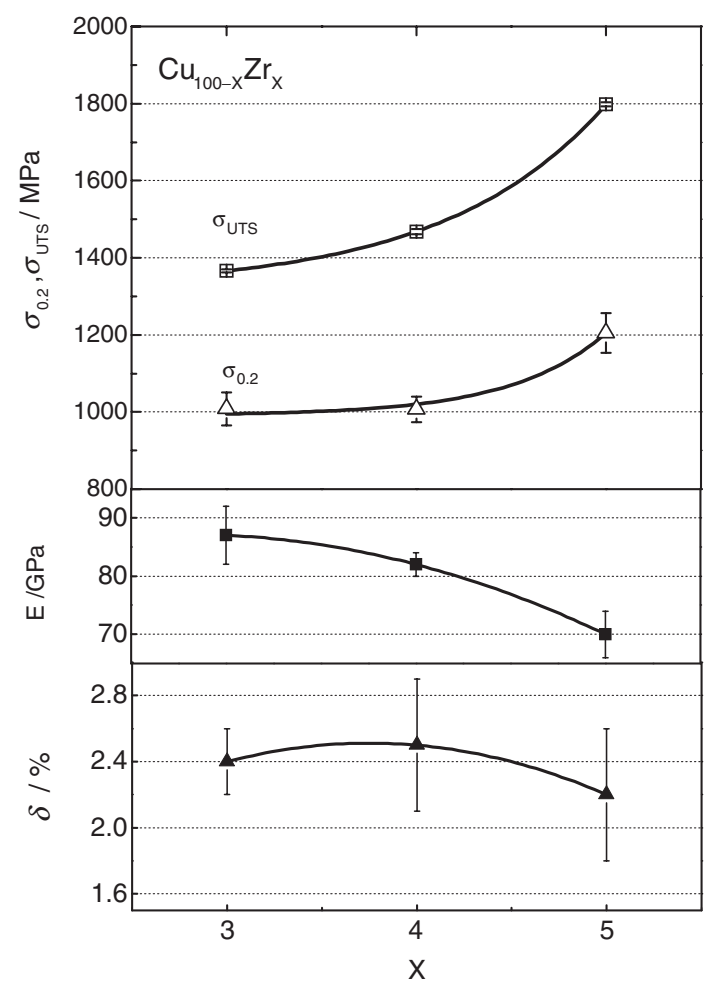

Fig. 4 The ultimate tensile strength $\left(\sigma_{\mathrm{UTS}}\right), 0.2 \%$ proof strength $\left(\sigma_{0.2}\right)$, Young's modulus $(\mathrm{E})$ and elongation $(\delta)$ as a function of $x$ content for the cold drawn $\mathrm{Cu}_{100-x} \mathrm{Zr}_{x}(x=3,4$ and 5 at $\%)$ alloy wires.

surface. These vein patterns are observed in SEM fractographs of the cold worked $\mathrm{Cu}$-Ti alloy with ductile mode. ${ }^{16)} \mathrm{It}$ is also observed that the vein pattern is elongated to the shear sliding direction. It is noted that the features of deformation and fracture modes agree with those of amorphous, ${ }^{17}$ ) glassy, ${ }^{18)}$ nanocrystalline ${ }^{19)}$ and nanoquasicrystalline ${ }^{20)}$ alloys. Figure 4 shows the ultimate tensile strength $\left(\sigma_{\mathrm{UTS}}\right)$, $0.2 \%$ proof strength $\left(\sigma_{0.2}\right)$, Young's modulus $(\mathrm{E})$ and elongation $(\delta)$ as a function of $\mathrm{Zr}$ content for the cold drawn $\mathrm{Cu}_{100-x} \mathrm{Zr}_{x}(x=3,4$ and $5 \mathrm{at} \%)$ alloy wires. As the $\mathrm{Zr}$ content increases, the yield strength and ultimate tensile strength increase gradually from $1008 \pm 43 \mathrm{MPa}$ and $1366 \pm$ $4 \mathrm{MPa}$, respectively, at $3 \% \mathrm{Zr}$ to $1007 \pm 33$ and $1468 \pm 7$ $\mathrm{MPa}$, respectively, at $4 \% \mathrm{Zr}$ and rapidly to $1205 \pm 52 \mathrm{MPa}$ and $1798 \pm 5 \mathrm{MPa}$, respectively, at $5 \% \mathrm{Zr}$. On the other hand, the Young's modulus decreases significantly from $87 \pm 5$ $\mathrm{GPa}$ at $3 \% \mathrm{Zr}$ to $70 \pm 4 \mathrm{GPa}$ at $5 \% \mathrm{Zr}$ and the elongation shows a nearly constant value of about $2.4 \pm 0.2 \%$. Thus, the cold drawn $\mathrm{Cu}_{95} \mathrm{Zr}_{5}$ alloy wire exhibits very high values of $1205 \pm 52 \mathrm{MPa}$ for $0.2 \%$ proof strength and $1798 \pm 5 \mathrm{MPa}$ for ultimate tensile strength in conjunction with the distinct elongation of $2.2 \pm 0.4 \%$. It is noticed that the ultimate tensile strength value is much higher than the highest ultimate tensile strength values (600 to $1500 \mathrm{MPa})$ for conventional crystalline $\mathrm{Cu}-\mathrm{Be}$ base alloys ${ }^{1,2)}$ and heavily cold-drawn $\mathrm{Cu}-\mathrm{M}(\mathrm{M}=\mathrm{Nb}$ or $\mathrm{Ag})$ alloys $\left.{ }^{2,3}\right)$ in the absence of significant difference in elongation. The Vickers hardness $(\mathrm{Hv})$ for $\mathrm{Cu}_{95} \mathrm{Zr}_{5}$ alloy wire is obtained to be 280 at room temperature from the measurement by micro Vickers hardness tester.

With the aim of clarifying the reason for the high tensile

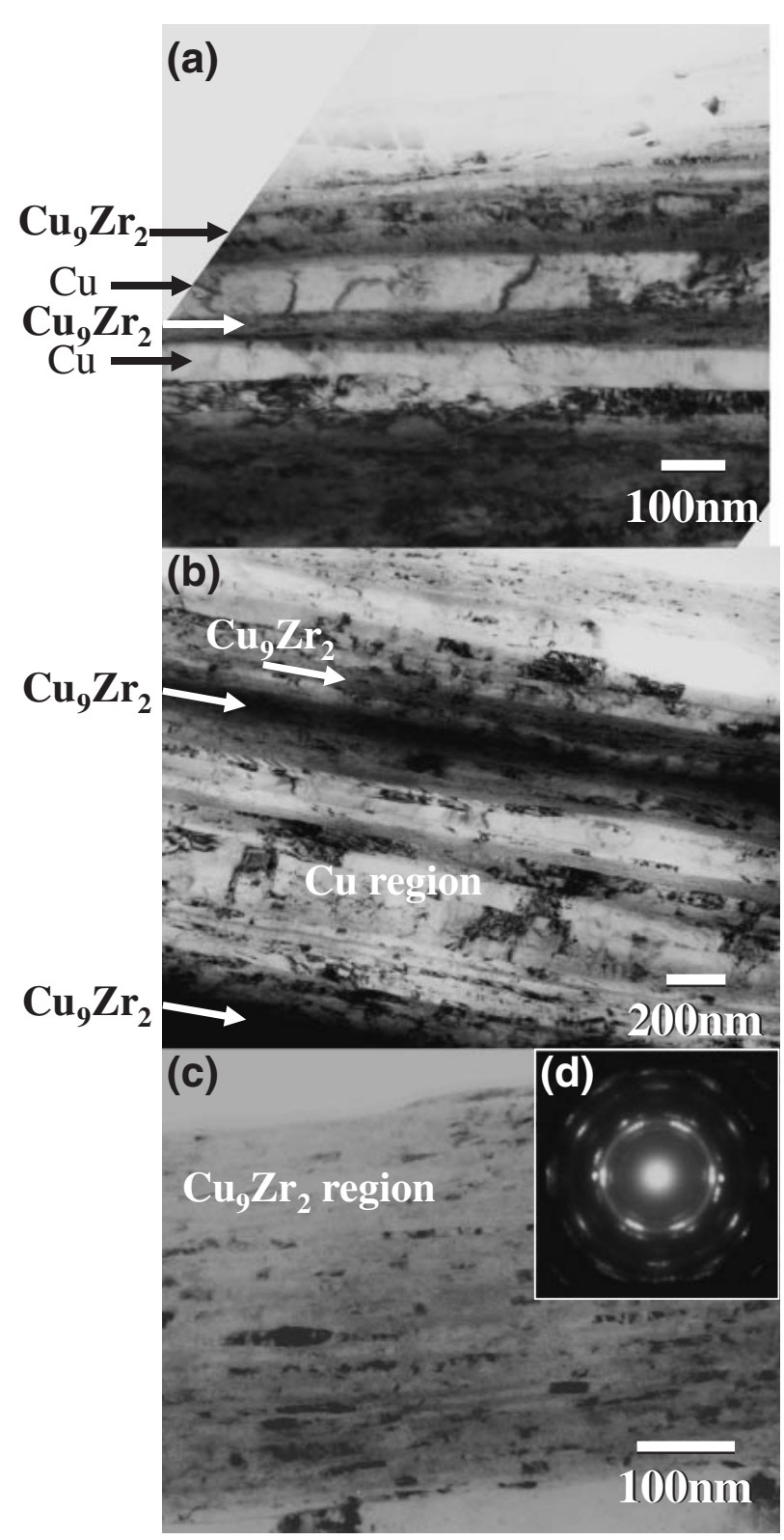

Fig. 5 (a, b, c) TEM micrographs of vertical cross section of the $\mathrm{Cu}_{95} \mathrm{Zr}_{5}$ alloy wire: bright field images and (d) diffraction pattern obtained from $\mathrm{Cu}_{9} \mathrm{Zr}_{2}$ phase region.

strength, the cold-drawn structure was examined by the high resolution TEM technique. As shown for the cold drawn $\mathrm{Cu}_{95} \mathrm{Zr}_{5}$ alloy wire with a reduction ratio of $99.7 \%$ in Figs. 5(a), (b), (c) and (d), the alloy wire has a well-developed fibrous structure of fcc-Cu and tetragonal $\mathrm{Cu}_{9} \mathrm{Zr}_{2}$ phases. In Fig. 5(a), the width of the constituent phases are measured to be about $90 \mathrm{~nm}$ for the $\mathrm{Cu}$ phase and about $70 \mathrm{~nm}$ for the $\mathrm{Cu}_{9} \mathrm{Zr}_{2}$ phase, respectively. As shown in Figs. 5(b), (c) and (d), high density of dislocations as well as numerous internal defects are seen in the fcc-Cu and $\mathrm{Cu}_{9} \mathrm{Zr}_{2}$ phases. The existence of such a high density of internal defects in the fcc$\mathrm{Cu}$ and $\mathrm{Cu}_{9} \mathrm{Zr}_{2}$ phase indicates clearly that both phases subjected to significant plastic deformation by the cold drawing treatment. The distinct development of the fibrous duplex structure caused by the large deformability of the dendritic fcc- $\mathrm{Cu}$ and the eutectic structure $\left(\mathrm{Cu}+\mathrm{Cu}_{9} \mathrm{Zr}_{2}\right)$ may be the origin for the achievement of the high tensile strength. 


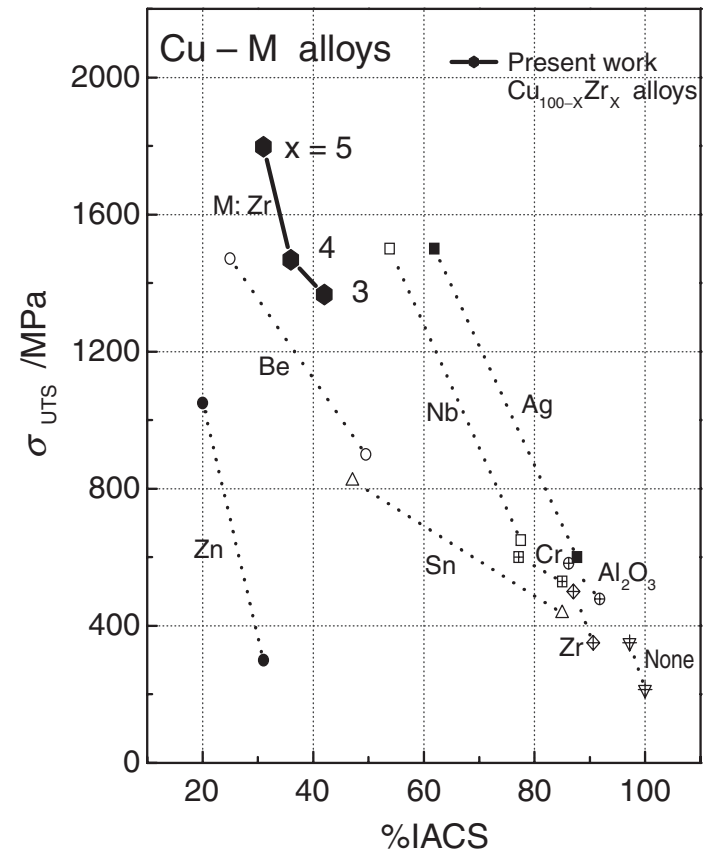

Fig. 6 Relationship between ultimate tensile strength ( $\left.\sigma_{\mathrm{UTS}}\right)$ and electrical conductivity (\%IACS) for the cold drawn $\mathrm{Cu}_{100-x} \mathrm{Zr}_{x}(x=3,4$ and 5 at\%) alloy wires. The data of conventional $\mathrm{Cu}$-based alloys are also shown for comparison.

Table 2 Tensile strength ( $\left.\sigma_{\mathrm{UTS}}\right)$, Vickers Hardness $\left(H_{V}\right)$ and electrical conductivity (\%IACS) for the cold-rolled and cold-drawn $\mathrm{Cu}_{100-x} \mathrm{Zr}_{x}$ binary alloys.

\begin{tabular}{crccccccc}
\hline & \multicolumn{3}{c}{$\sigma_{\text {UTS }}(\mathrm{MPa})$} & \multicolumn{6}{c}{$H_{V}$} & \% IACS \\
\hline$x$ & \multicolumn{1}{c}{3} & 4 & 5 & 5 & 3 & 4 & 5 & \\
\hline cold-rolled alloys & 880 & 1035 & 1095 & 260 & 40 & 40 & 35 & ref. 13) \\
cold-drawn alloys & 1366 & 1468 & 1798 & 280 & 42 & 36 & 31 & Present \\
\hline
\end{tabular}

It is expected that the well-developed fibrous structure consisting mainly of fcc-Cu phase for the $\mathrm{Cu}-\mathrm{Zr}$ alloys causes high electrical conductivity. The electrical conductivity of the three cold-drawn alloys was measured to be $42 \%$ IACS at $3 \% \mathrm{Zr}, 36 \% \mathrm{IACS}$ at $4 \% \mathrm{Zr}$ and $31 \% \mathrm{IACS}$ at $5 \% \mathrm{Zr}$ at $298 \mathrm{~K}$. Figure 6 shows the relationship between ultimate tensile strength and electrical conductivity for the cold drawn $\mathrm{Cu}_{100-x} \mathrm{Zr}_{x}(x=3,4$ and 5 at $\%)$ alloy wires. Table 2 shows the values of $\sigma_{\mathrm{UTS}}, \mathrm{Hv}$ and \%IACS for the cold-rolled $\mathrm{Cu}-\mathrm{Zr}$ binary alloys (plates) and cold-drawn ones (wires). As seen in the table, the values of $\sigma_{\text {UTS }}$ for the wires are much larger than those for the plates, while the values of \%IACS of the wires are almost same to those of the plates. The high tensile strength of the wires is considered to be caused by formation of fibrous duplex structure as mentioned above. In comparison with those for conventional $\mathrm{Cu}$-based alloys, it is noticed that the present $\mathrm{Cu}-\mathrm{Zr}$ binary alloy wires have much better combination of higher ultimate tensile strength and high electrical conductivity values. ${ }^{6}$ )

\section{Summary}

In conclusion, we have noticed that ultrahigh tensile strength of 1350 to $1800 \mathrm{MPa}$ and high electrical conductiv- ity of 30 to $45 \%$ IACS are simultaneously obtained for the $\mathrm{Cu}_{100-x} \mathrm{Zr}_{x}(x=3,4$ and 5 at $\%)$ alloys subjected to copper mold casting, followed by cold drawing to $99.7 \%$ reduction in cross section. The combination of strength and electrical conductivity exceeds the best combination values of $\mathrm{Cu}-\mathrm{Be}$ and $\mathrm{Cu}-\mathrm{M}(\mathrm{M}=\mathrm{Nb}$ or $\mathrm{Ag})$ alloys reported up to date. The cold-drawn $\mathrm{Cu}_{95} \mathrm{Zr}_{5}$ alloy wire has a fibrous mixed structure of fcc- $\mathrm{Cu}$ and $\mathrm{Cu}_{9} \mathrm{Zr}_{2}$ phases. The unique fibrous structure developed in the cold-drawn $\mathrm{Cu}-\mathrm{Zr}$ alloy wires may be the origin for the simultaneous achievements of high tensile strength and high electrical conductivity which are expected to cause practical uses as a new type of high strength and high electrical conductivity materials.

\section{Acknowledgements}

This work was done as a part of the activities of the Nanotechnology Metal Project under the auspices of the Japan Research and Development Centere for Metals (JRCM) and sponsorship from New Energy and Industrial Technology Development Organization (NEDO, Ministry of Economics, Trade and Industry). We would like to thank Dr. O. Haruyama of Faculty of Science and Technology, Tokyo University of Science and Mr. K. Amiya, Mr. K. Wakoh and Mr. K. Sasamori of Institute for Materials Research, Tohoku University for his great helpful advice and assistance.

\section{REFERENCES}

1) J. C. Harkness, W. D. Spiegelberg and W. R. Cribb: Metals Handbook, 10th Edition, ed. By J. R. Davis and P. Allen, (1990, The Materials Information Society) Vol. 2, pp. 403-427.

2) from Catalog (Nov. 2003) by NGK INSULATORS, LTD.

3) W. A. Spitzig, A. R. Pelton and F. C. Laabs: Acta metal 35 (1987) 2427-2442.

4) Y. Sakai, K. Inoue, H. Wada and H. Maeda: J. Jpn Inst. Metals 55 (1991) 1382-1391.

5) Y. Sakai, K. Inoue, T. Asano, H. Wada and H. Maeda: Appl. Phys. Lett. 59 (1991) 2965-2967.

6) Y. Sakai and H. J. Schneider-Muntau: Acta mater. 45 (1997) 10171023.

7) A. Inoue, W. Zhang, T. Zhang and K. Kurosakak: Acta Mater 49 (2001) 2645-2652.

8) A. Inoue and W. Zhang: Mater. Trans 43 (2002) 2921-2925.

9) A. Inoue, W. Zhang, T. Zhang, K. Kurosaka and D. V. Louzguine: J. Metastable and Nanocrystalline Materials 15-16 (2003) 3-10.

10) A. Inoue and W. Zhang: Mater. Trans 45 (2004) 584-587.

11) T. H. Ourtney: ASM Handbook, ed. by George E. Dieter, (1997, The Materials Information Society) Vol. 20, pp. 336-356.

12) I. Ochiai, S. Nishida, H. Ohba and A. Kawana: TETSU-TO-HAGANE 79 (1993) 1101-1107.

13) H. Kimura, A. Inoue, K. Sasamori, H. Yoshida and O. Haruyama: Mater. Trans. 46 (2005) 1733-1736.

14) J. L. Glimois, P. Forey and J. L. Feron: J. Less-Common Metals 113 (1985) 213-224.

15) D. Arias and J. P. Abriata: Bull. Alloy Phase Diagram 11 (1990) 452459.

16) S. Nagarjuna and Balasubramanian: J. Mater. Sci. 34 (1999) 29292942.

17) T. Masumoto and H. Kimura: Sci. Rep. RITU A25 (1975) 200-215.

18) A. Inoue, T. Zhang and T. Masumoto: Mater. Trans. JIM 36 (1995) 391-398.

19) Y. H. Kim, A. Inoue and T. Masumoto: Mater. Trans., JIM 32 (1991) 331-338.

20) A. Inoue, M. Watanabe, H. M. Kimura, F. Takahashi, A. Nagata and T. Masumoto: Mater. Trans., JIM 33 (1992) 723-729. 